\title{
Pharmacokinetically guided phase I trial of topotecan and etoposide phosphate in recurrent ovarian cancer
}

\author{
NC Levitt', DJ Propper², S Madhusudan', JP Braybrooke³, C Echeta', R te Poele², SL Davies ${ }^{4}$, E Flanagan', \\ ID Hickson ${ }^{4}$, S Joel ${ }^{2}$ and TS Ganesan*,I
}

'Cancer Research UK Cancer Centre, Churchill Hospital, Oxford OX3 7LJ, UK; ${ }^{2}$ Cancer Research UK, Medical Oncology Unit, St Bartholomew's Hospital, West Smithfield, London ECIA 7BE, UK; ${ }^{3}$ Genome Integrity Group, Molecular Oncology Laboratories, Weatherall Institute of Molecular Medicine, John Radcliffe, Hospital, Oxford OX3 9DS, UK; ${ }^{4}$ Bristol Haematology and Oncology Centre, Horfield Road, Bristol BS2 8ED, UK

\begin{abstract}
A pharmacokinetically guided phase I study of topotecan and etoposide phosphate was conducted in recurrent ovarian cancer. The scheduling of the topoisomerase I and II inhibitors was determined using in vitro activity data. All patients had recurrent disease following prior platinum-containing chemotherapy. Patients had a World Health Organisation performance status of 0-2 and adequate bone marrow, renal and hepatic function. Treatment was with topotecan intravenously for 5 days followed immediately by a 5-day intravenous infusion of etoposide phosphate (EP), with pharmacokinetically guided dose adjustment. Plasma etoposide levels were measured on days 2 and 4 of the infusion. A total of 21 patients entered the study. In all, $48 \%$ were platinum resistant and 7 I\% had received prior paclitaxel. The main toxicities were haematological, short lived and reversible. A total of $29 \%$ of patients experienced grade 4 thrombocytopenia and $66 \%$ grade 4 neutropenia after the first cycle. Neutropenia and thrombocytopenia was dose limiting. The maximum-tolerated dose was topotecan $0.85 \mathrm{mg} \mathrm{m}^{-2}$ day $^{-1}$ days I - 5 followed immediately by a 5 -day infusion of $\mathrm{EP}$ at a plasma concentration of $\mathrm{I} \mu \mathrm{g} \mathrm{ml}^{-1}$. The response rate (RR) was $28 \%$ in 18 evaluable patients. There was marked interpatient variability in topoisomerase $\mid l \alpha$ levels measured from peripheral lymphocytes, with no observed increase following topotecan. This regimen of topotecan followed by EP demonstrated good activity in recurrent ovarian cancer and was noncrossresistant with paclitaxel. Both the toxicity and RR was higher than would be expected from the single agent data, in keeping with synergy of action. British Journal of Cancer (2005) 93, 60-69. doi:I0.1038/sj.bjc.6602657 www.bjcancer.com
\end{abstract}

Published online 14 June 2005

(C) 2005 Cancer Research UK

Keywords: topotecan; etoposide phosphate; topoisomerases; ovarian cancer

Advanced ovarian carcinoma is usually sensitive to chemotherapy with durable complete remissions but relapse often occurs, necessitating further treatment. Evaluation of appropriate active regimens for patients with recurrent or resistant ovarian cancer allows the possibility of eventually incorporating them into initial management (Stuart, 2003). The initial treatment for advanced ovarian cancer comprises cytoreductive surgery followed by platinum-containing chemotherapy with or without paclitaxel (McGuire et al, 1996; Muggia et al, 2000; Piccart et al, 2000; ICON3 collaborators, 2002). Effective noncrossresistant second- and thirdline therapies are required. This study evaluates the sequential combination of topotecan and etoposide phosphate (EP).

Topotecan (Hycamtin; SmithKline Beecham Pharmaceuticals, Philadelphia, PA, USA) is a semisynthetic analogue of the plant alkaloid camptothecin which is a topoisomerase I inhibitor and is active in ovarian cancer. According to phase I trials, the best schedule and maximum-tolerated dose (MTD) of topotecan is $1.5 \mathrm{mg} \mathrm{m}^{-2}$ day $^{-1}$ for 5 consecutive days in a 21-day cycle (Rowinsky and Verweij, 1997). In phase I studies of topotecan, the main dose-limiting side effect was neutropenia, which was

*Correspondence: Dr TS Ganesan; E-mail: ganesan@cancer.org.uk Received 24 January 2005; revised 9 May 2005; accepted 9 May 2005; published online 14 June 2005 predictable, of short duration and noncumulative. Other side effects included thrombocytopenia, alopecia and gastrointestinal toxicity. Mucositis, fatigue, rashes and abnormalities of liver function were also rarely reported. Phase II studies have shown activity and prolonged disease stabilisation in patients with recurrent ovarian cancer (Creemers et al, 1996; Kudelka et al, 1996). This was also observed in patients whose disease had progressed following prior chemotherapy with paclitaxel or platinum agents (Bookman et al, 1998; Gore et al, 2001). A randomised phase III study that compared topotecan to paclitaxel as second-line therapy after platinum-containing regimens showed a higher response rate (20.5 vs 13.2\%, $P=0.138$ ), longer response duration (32 vs 20 weeks, $P=0.222$ ) and longer time to progression (23 vs 14 weeks, $P=0.002$ ) for topotecan, although there was no significant improvement in survival (ten Bokkel Huinink et al, 1997). In view of these studies, topotecan has been licensed as a second-line therapeutic agent for ovarian cancer. More recently, a shorter 3-day infusion of topotecan $1.5 \mathrm{mg} \mathrm{m}^{-2}$ day $^{-1}$ in advanced ovarian cancer has shown similar activity but was less toxic than standard treatment (Markman et al, 2000).

Etoposide, a topoisomerase II inhibitor, has antitumour activity in a wide range of tumours including small-cell lung cancer (SCLC), germ cell tumours of the testis and lymphomas. Etoposide has been given in a variety of schedules both as a single agent and 
in combination therapy in a number of tumour types (Hande, 1998). Response to etoposide is dependent on drug scheduling as its activity is specific to S-phase of the cell cycle (Joel et al, 1998).

Oral etoposide has been investigated as a route of prolonged administration (Hainsworth et al, 1989). Although oral schedules maintain low plasma etoposide levels throughout the treatment period, plasma concentrations still vary between peak and pretreatment levels. Additionally, the absorption of oral etoposide is incomplete (60\% bioavailability) and variable, both between and within patients (Harvey et al, 1985b; Slevin and Joel, 1993). Phase II studies with oral etoposide showed response rates of 24 and $26 \%$ in patients with relapsed or platinum-resistant ovarian cancer (Hoskins and Swenerton, 1994; Seymour et al, 1994). Myelotoxicity was dose limiting in both studies. A third phase II study showed response rates of $34.1 \%$ in platinum-sensitive patients and $26.8 \%$ in platinum-resistant patients. Almost one-third of platinumresistant responders had also received paclitaxel (Rose et al, 1998). The main toxicities were haematological. Thus, oral etoposide is noncrossresistant with both platinum agents and paclitaxel.

EP (Etopophos, Bristol Myers Squibb Co, Princeton, NJ, USA) is rapidly converted to etoposide in the blood. It is approximately 20 times more soluble than etoposide and can therefore be given as a prolonged outpatient infusion. A recent phase II study has evaluated the efficacy of EP in patients with relapsed or resistant ovarian carcinoma, previously treated with both carboplatin and paclitaxel (O'Byrne et al, 1997). To ensure that target concentrations were achieved rapidly, a loading dose of EP was given intravenously over $30 \mathrm{~min}$. At the same time, a constant infusion of EP was commenced to maintain plateau levels at the target concentration. Plasma drug monitoring was performed $24 \mathrm{~h}$ into the infusion and at 3 days, with infusion rate modification if necessary to ensure that target levels were achieved. In the first cohort of 16 patients treated with EP to achieve a plasma level of $2 \mu \mathrm{g} \mathrm{ml}^{-1}$, no objective responses were observed although disease stabilisation occurred in four patients. The next cohort of patients were treated at $3 \mu \mathrm{g} \mathrm{ml}^{-1}$. Of 28 patients, 26 were evaluable and the response rates were $43 \%$ for platinum-sensitive patients and $17 \%$ for platinum-resistant patients. In all, $20 \%$ of patients in the second cohort experienced grade 4 myelosuppression, suggesting that in heavily pretreated patients with ovarian cancer, the single agent dose of EP is $3 \mu \mathrm{g} \mathrm{ml}^{-1}$ infused for 5 days.

There are theoretical reasons and some preclinical data to suggest that topotecan and etoposide may act synergistically in sequential combination with the schedule of administration being important (Whitacre et al, 1997). A proposed mechanism for synergy is that topoisomerase I inhibitors increase topoisomerase II $\alpha$ levels, sensitising malignant cells to the effects of topoisomerase II inhibition (Whitacre et al, 1997). Thus, the sequential administration of topotecan followed by EP might lead to total topoisomerase 'shutdown' and synergistic antitumour activity.

This study assesses the combination of a 5-day schedule of topotecan followed closely by a continuous 5-day infusion of EP for toxicity and to identify the MTD of both drugs, in patients with recurrent or platinum-resistant ovarian carcinoma. In addition, the combination of both drugs was studied in vitro to evaluate the schedule and potential synergy.

\section{PATIENTS AND METHODS}

\section{Eligibility}

The study was open to patients with histologically confirmed epithelial ovarian carcinoma, primary serous papillary peritoneal carcinoma or fallopian tube carcinoma and evaluable, relapsed or platinum-resistant disease. Platinum-resistant disease was defined as progression on treatment or relapse within 6 months of completion of initial treatment. Patients were required to be over
18 years old and with a World Health Organisation (WHO) performance status of $0-2$. They were required to have adequate bone marrow (neutrophils $\geqslant 1.5 \times 10^{9} 1^{-1}$, platelets $\geqslant 100 \times 10^{9} 1^{-1}$ ), renal (normal serum creatinine and EDTA clearance $>40 \mathrm{ml} \mathrm{min}^{-1}$ ) and hepatic function (serum bilirubin $<50 \mu \mathrm{moll}^{-1}$, albumin $>30 \mathrm{gl}^{-1}$, aspartate amino transferase and alkaline phosphatase $\leqslant 3$ times the upper limit of normal or $\leqslant 5$ times the upper limit of normal in the presence of liver metastases). All patients had recovered from the acute toxic effects of previous treatment and had not received radiotherapy, chemotherapy or immunotherapy within 4 weeks of trial entry. Pregnant women, nursing mothers and patients not using adequate contraception were excluded, as were patients with clinical evidence of cerebral metastases. All patients gave written informed consent for the trial and for insertion of a Hickman line to allow drug delivery. The trial was approved by the local research ethics committee and was conducted according to the recommendations of the Declaration of Helsinki, Hong Kong Amendment 1989 and the ABPI guidelines for good clinical practice.

\section{Study design}

This single centre phase I study used a modified Fibonacci design with a planned minimum of three patients at each dose level. As both chemotherapy agents in this study are myelotoxic, topotecan was given at $1.0 \mathrm{mg} \mathrm{m}^{-2}$ day $^{-1}$ consecutively for days $1-5$, twothird of its usual recommended dose. This was followed by a continuous infusion of EP, achieving a plasma concentration of etoposide of $2 \mu \mathrm{g} \mathrm{ml}^{-1}$ for days 6-10 in dose level 1a and adjusted thereafter according to toxicity. Dose levels used in this study are listed in Table 1. This starting dose was chosen following a phase II study of EP alone (O'Byrne et al, 1997), in which a dose level of $2 \mu \mathrm{g} \mathrm{ml}^{-1}$ for 5 days was well tolerated. Patients were retreated in four weekly cycles. Standard antiemetic cover was with metoclopramide, as required. Dexamethasone and tropisetron were used if patients had persistent nausea. Patients were also routinely given warfarin $1 \mathrm{mg}$ once daily as prophylaxis against Hickman lineinduced venous thrombosis. Granulocyte colony-stimulating factor was not given in this study.

Dose escalation to higher levels was planned providing that no patient in the cohort experienced dose-limiting toxicity (DLT). If however, two out of three or three out of six patients in a single dose level experienced DLT, then it was planned to stop recruiting at that level and to include additional patients at a lower dose level. As it was anticipated that myelotoxicity might be dose limiting even at dose level la, further (lower) dose escalation schemes were devised. As patients who have received both paclitaxel and carboplatin in the past may have less marrow reserve than patients who have only received carboplatin, it was planned to expand the MTD level to include at least four patients who had previously been treated with both agents.

Dose-limiting toxicity was defined using the CALBG (Cancer and Leukemia Group B) common toxicity grading, as grade 4 haematological toxicity during the first cycle of treatment (grade 4 thrombocytopenia or grade 4 neutropenia lasting for more than 5 days or complicated by fever), or grade 3 nonhaematological

Table I Topotecan and etoposide dose levels

\begin{tabular}{|c|c|c|}
\hline Dose level & Topotecan ( $\left.\mathrm{mg} \mathrm{m}^{-2} \mathrm{day}^{-1}\right)$ & Etoposide level $\left(\mu \mathrm{g} \mathrm{ml}^{-1}\right)$ \\
\hline Ia & 1.0 & 2.0 \\
\hline Ib & 0.85 & 2.0 \\
\hline $2 \mathrm{a}$ & 0.85 & 1.0 \\
\hline $2 b$ & 0.85 & 1.5 \\
\hline
\end{tabular}


toxicity (excluding nausea, vomiting and alopecia) or grade 4 vomiting in patients with maximal antiemetic supportive care. As it was probable that myelotoxicity would be cumulative, only first cycle effects were defined as contributing to DLT. The stop dose was defined as the dose at which two out of three or three out of six patients experienced DLT. Maximum-tolerated dose was defined as the highest dose level at which no more than one out of six patients experienced DLT. The MTD is therefore the dose below the stop dose level.

In the 2 weeks prior to recruitment into the study, patients were assessed by clinical examination and with a chest radiograph, EDTA (ethylene diamine tetra-acetic acid) clearance, full blood count and differential, serum electrolytes, including calcium and phosphate, creatinine and urea, liver function tests, Ca125 and urinalysis. Within 4 weeks of recruitment, all patients had full assessment of any measurable/evaluable lesions by CT scan of abdomen and pelvis and by other investigations such as clinical photography, CT thorax, MRI or bone scans as clinically indicated. Blood tests and urinalysis were repeated on the day prior to starting treatment, before each subsequent cycle and 2 weeks after completing the study. Dose reductions to the next lowest dose level were made if patients experienced any grade 4 haematological or grade 3 nonhaematological toxicity (excluding alopecia). Treatment in subsequent cycles was delayed until the toxicity had resolved. Quality of life (QOL) was assessed with the EORTC (European Organisation for Research and Treatment of Cancer) 30 questionnaire prior to cycles 1,3 and 6 .

Patients, who tolerated the chemotherapy and had stable or responding disease after three cycles, were continued on study for a maximum of six cycles. If there was evidence of progressive disease, then treatment was stopped after a minimum of two cycles. The response to treatment was formally assessed after three and six cycles. Disease response was assessed according to World Health Organisation (WHO) criteria. The duration of response was calculated as the period from the final course of chemotherapy through to the date of confirmed relapse.

\section{Drug formulation and administration}

Topotecan was reconstituted in sterile saline and given as an infusion via a Hickman line over $30 \mathrm{~min}$, on days $1-5$ of each cycle. Bristol-Myers Squibb Pharmaceuticals supplied EP, as $113.6 \mathrm{mg}$ of lyophilised powder in a sterile glass vial. Each vial was reconstituted with sterile saline. Starting on day 6, EP was infused via a Hickman line, starting with a loading dose of $10 \times$ target etoposide level $\mathrm{mg} \mathrm{m}^{-2}$, given over $30 \mathrm{~min}$, followed by a 5 -day continuous infusion in $\mathrm{mg} \mathrm{m}^{-2} \mathrm{~h}^{-1}$. The initial infusion rate was calculated and adjusted according to measured plasma etoposide concentrations (Joel et al, 1996).

\section{Therapeutic drug monitoring}

Etopside phosphate was commenced on the afternoon of day 6 . On the morning of day 7 ( $18 \mathrm{~h}$ after the start of the infusion) and on day 9 of each cycle, peripheral venous blood samples were drawn for determination of total plasma etoposide levels, as described previously (Harvey et al, 1985a; Joel et al, 1996, 1998). Plasma standards covering the range $0.5-5.0 \mathrm{mg} \mathrm{ml}^{-1}$ were used; patient samples were run in duplicate, with quality control samples at two concentrations $\left(1.25\right.$ and $\left.3.5 \mathrm{mg} \mathrm{ml}^{-1}\right)$. Between-assay reproducibility based on these quality control samples was $<10 \%$. Plasma etoposide concentration was obtained on the day of sampling, with a typical turn-around time of $3-4 \mathrm{~h}$ to permit adjustment of the infusion rate on that day. Dose modifications were made according to the measured steady-state plasma etoposide concentration using the following formula: (Joel et al, 1996)

$$
\begin{aligned}
& \text { New continuous infusion }(\mathrm{CI}) \text { dose }\left(\mathrm{mg} \mathrm{h}^{-1}\right)= \\
& \text { Current } \mathrm{CI}\left(\mathrm{mg} \mathrm{h}^{-1}\right) \times \frac{\text { Target plasma concentration }}{\text { Measured plasma concentration }}
\end{aligned}
$$

Adjustments to the infusion rate were only made if the measured plasma etoposide concentration differed by $>10 \%$ from the target concentration. The initial infusion rates for cycles 2-6 were based on the plasma etoposide concentration from the preceding cycle.

\section{Preclinical evaluation of cell lines}

Ovarian cancer cell lines (A2780, SKOV-3 and OVCAR-3) were cultured in RPMI 1640 medium supplemented with $10 \%$ foetal bovine serum, penicillin $100 \mathrm{U} \mathrm{ml}^{-1}$ and streptomycin $100 \mu \mathrm{g} \mathrm{ml}^{-1}$ (Gibco BRL, Paisley, UK). Cells were incubated at $37^{\circ} \mathrm{C}$ in a humidified atmosphere containing $5 \% \mathrm{CO}_{2}$. Stock solutions of the topoisomerase I inhibitor, SN-38 (gift from Aventis Pharma, France) were prepared in DMSO (dimethylsulphoxide, Sigma, Dorset, UK), and etoposide (Sigma) in 50\% methanol. These were diluted to the appropriate concentrations in media immediately prior to use. The final concentration of DMSO in the culture medium was $<0.02 \%$. Cells were plated at a density of $2 \times 10^{5} \mathrm{ml}^{-1}$ and allowed to attach for $24 \mathrm{~h}$ prior to drug treatment. The activity of $\mathrm{SN}-38$ and etoposide as single agents was first determined across a range of concentrations $\left(0-100 \mathrm{ng} \mathrm{ml}^{-1} \mathrm{SN}-38,0-10 \mu \mathrm{M}\right.$ etoposide). The concentration of each drug resulting in $10 \%$ apoptosis after 3 days was determined from concentration effect curves using a sigmoidal $E_{\mathrm{MAX}}$ model and used in subsequent combination experiments. These concentrations were $3.125 \mathrm{ng} \mathrm{ml}^{-1}$ for SN-38 in each cell line, $2 \mu \mathrm{M}$ etoposide in A2780, $1 \mu \mathrm{M}$ etoposide in OVCAR-3 and $3 \mu \mathrm{M}$ etoposide in SKOV3. Drug medium was replaced every $24 \mathrm{~h}$, with detached cells harvested by centrifugation and resuspended in the fresh drug medium.

Cell cycle distribution, including the apoptotic (sub-G0/G1) population, was determined using propidium iodide following the controlled extraction of low molecular weight DNA. Cells were harvested by trypsinisation and centrifugation, and fixed in $70 \%$ ethanol overnight. After removal of fixative, cells were resuspended in $750 \mu \mathrm{l}$ of DNA extraction buffer $\left(96 \% 0.2 \mathrm{M} \mathrm{Na} \mathrm{Na}_{2} \mathrm{HPO}_{4}\right.$, $4 \% 0.1 \mathrm{M}$ citric acid) for $5 \mathrm{~min}$ at room temperature. Buffer was removed by centrifugation and the cells were resuspended in DNA staining solution $\left(50 \mu \mathrm{g} \mathrm{ml}^{-1}\right.$ propidium iodide and $50 \mu \mathrm{g} \mathrm{ml}^{-1}$ ribonuclease A, Sigma) for $1 \mathrm{~h}$ in the dark. Fluorescence data from 10000 cells was collected on a FACScan flow cytometer (Becton Dickinson) and analysed using LYSYS II software. Results presented are the mean of a minimum of three separate experiments. Statistical comparisons were made using a paired $t$-test.

\section{Peripheral blood topoisomerase II $\alpha$ levels}

In all, $10 \mathrm{ml}$ blood samples were taken into iced cold EDTA containers on days 1,6 and 10 of cycle one for topoisomerase II $\alpha$ analysis. Samples were processed immediately; $5 \mathrm{ml}$ of blood was layered onto $5 \mathrm{ml}$ lymphoprep (Nycomed Pharma AS Diagnostics, Oslo, Norway) and centrifuged for $20 \mathrm{~min}$ at $4^{\circ} \mathrm{C}$. The lymphocyte layer was washed once with phosphate-buffered saline and recentrifuged. The cell pellet was resuspended in $2 \times$ SDS sample buffer and incubated at $90^{\circ} \mathrm{C}$ for $10 \mathrm{~min}$ before freezing at $-70^{\circ} \mathrm{C}$. Polyacrylamide gel electrophoresis and Western blotting was performed as previously described (Ausubel et al, 1994). Blots were probed with a monoclonal anti-topoisomerase II $\alpha$ antibody, 1 F6 (Negri et al, 1992). $\beta$-Tubulin (monoclonal anti- $\beta$-tubulin clone 2.1, Sigma, Missouri, USA) was used as a loading control. Autoradiographs were scanned and the band intensity of the lanes compared using FluorChem software, with the tubulin band as a control for each sample. 


\section{RESULTS}

\section{Patients and treatment}

A total of 21 patients were entered into this study (Table 2). One patient's performance status fell from 2 when she was consented for the trial to 3 on day 1 of the study. All patients had received previous platinum-containing chemotherapy and 15 out of 21 (71\%) had also received paclitaxel (Table $3 \mathrm{a})$. Only two patients (10\%) progressed through first-line platinum-containing chemotherapy. A total of 10 patients (48\%) either progressed following first-line chemotherapy or had duration of response of less than 6 months and were therefore classified as platinum-resistant (Table 3a). A total of 15 patients had received two or more chemotherapy regimens (Table $3 \mathrm{~b}$ ). One patient had had prior exposure to etoposide, given orally as third-line chemotherapy.

In this study, a total of 100 cycles of trial chemotherapy were given with a mean of 4.8 cycles per patient. A total of 12 patients completed all six planned cycles of chemotherapy.

\section{Toxicity}

The main toxicity was myelosuppression (Table 4). Both patients entered at dose level 1a (T-1.0/E-2.0) experienced grade 4 neutropenia with associated sepsis following the first cycle of treatment and therefore the next patient was recruited to the lower dose level of $1 \mathrm{~b}$ (T-0.85/E-2.0). This dose level also proved to be excessively myelotoxic, with all three patients suffering grade 4 neutropenia, two with associated sepsis. Dose level 2a (T-0.85/E-1.0) was better tolerated and was therefore expanded to 11 patients in order to allow for better assessment of toxicity at this dose level. Four of these patients experienced grade 4 neutropenia, however this was for fewer than 5 days and was complicated by sepsis in only one case. As DLT at dose level 2 a was observed in only one of 11 patients, a higher dose level, $2 \mathrm{~b}$ (T-0.85/E-1.5) was given to a further five patients. Dose-limiting toxicity was also seen at this dose level, with grade 4 neutropenia complicated by sepsis in four out of five patients. Of 13 patients with grade 4 neutropenia during cycle 1,10 became septic. This high incidence of neutropenic sepsis may reflect the heavy pretreatment of this patient group and the fact that neither prophylactic antibiotics nor G-CSF were given in this trial. There were no deaths from neutropenic sepsis. Of note, the haematological toxicity in this study was of short duration with only three out of 21 patients having a treatment delay of $\geqslant 1$ week at cycle 2 . Nonhaematological toxicity was not dose limiting, detailed in Table 4 . Generally this was mild and manageable with grade 3 toxicities of nausea, stomatitis and diarrhoea seen in three, one and one patients, respectively.

\section{Pharmacokinetics}

All patients had pharmacokinetic sampling during each treatment cycle, with adjustment of the infusion rate to achieve the targeted plasma etoposide level. The starting infusion rate for cycle 1 did not allow for differences in renal function, as the total etoposide plasma

clearance correlated only poorly with the EDTA creatinine clearance (Figure 1). The starting infusion rate for cycle 2 and subsequent cycles was the same as the final infusion rate from the preceding cycle.

There was considerable interpatient variability in the measured plasma etoposide levels (Figure 2). Across all cycles, samples from day 2 showed that $32 \%$ of patients had measured plasma etoposide levels within $10 \%$ of the target level. This improved to a mean of $58 \%$ for day 4 measurements. Measured etoposide levels were within $20 \%$ of the target level for $66 \%$ of patients on day 1 and $85 \%$ by day 4 . Patients with measured etoposide levels more or less than $10 \%$ from the target level had their etoposide phosphate infusion adjusted. Table 5 details the number of patients for each cycle for whom this was necessary.

\section{Tumour responses at the end of treatment}

A total of 18 patients were evaluable for tumour response, having completed at least three cycles of treatment. Objective tumour

Table 3a Previous treatment - first-line chemotherapy

\begin{tabular}{lccc}
\hline & Carboplatin & $\begin{array}{c}\text { Carboplatin+ } \\
\text { paclitaxel }\end{array}$ & $\begin{array}{c}\text { Cisplatin- } \\
\text { containing } \\
\text { regimens }\end{array}$ \\
\hline Number of patients & 12 & 7 & 2 \\
CR & 5 & 4 & 2 \\
PR & 3 & 3 & 0 \\
SD & 2 & 0 & 0 \\
PD & 2 & 0 & 0 \\
Platinum sensitive & $7 / 12$ & $3 / 7$ & $1 / 2$ \\
Mean duration of first & 18.0 & 6.3 & 9.0 \\
remission (min) (excluding & & & \\
patients with PD) & & & \\
\hline
\end{tabular}

$\mathrm{CR}=$ complete remission; $\mathrm{PR}=$ partial remission; $\mathrm{SD}=$ stable disease; $\mathrm{PD}=$ progressive disease.

Table 3b Previous treatment - second- and third-line chemotherapy

\begin{tabular}{c}
$\begin{array}{c}\text { Second-line } \\
\text { chemotherapy }\end{array} \begin{array}{c}\text { Third-line } \\
\text { chemotherapy }\end{array}$ \\
\hline
\end{tabular}

Treatment

Total CR PR SD PD Total CR PR SD PD

\begin{tabular}{|c|c|c|c|c|c|c|c|}
\hline Carboplatin & 3 & I & I & I & & & \\
\hline Paclitaxel & 4 & 2 & । & । & 2 & I & । \\
\hline Carboplatin+paclitaxel & 2 & 2 & & & & & \\
\hline CAP & 2 & & & 2 & & & \\
\hline FEC & । & & & I & & & \\
\hline Cyclophosphamide+epirubicin & । & & & I & & & \\
\hline Oral etoposide & & & & & I & & I \\
\hline Noncytotoxic - trial treatment & 2 & । & I & & । & I & \\
\hline
\end{tabular}

Table 2 Patient details

\begin{tabular}{|c|c|c|c|c|c|c|c|}
\hline \multicolumn{2}{|l|}{ Age and PS } & \multicolumn{2}{|l|}{ Histology } & \multicolumn{2}{|c|}{ Stage at presentation } & \multicolumn{2}{|l|}{ Previous surgery } \\
\hline Number of patients, $n$ & 21 & Ovary - serous & 12 & Stage I & 0 & $\mathrm{TAH}, \mathrm{BSO}$ and omentectomy & 9 \\
\hline Age - mean & 54 & Ovary - endometroid & 4 & Stage ॥ & | & $\mathrm{BSO}$ and $\mathrm{TAH}$ & 3 \\
\hline Age - range & $31-66$ & Ovary - clear cell & 1 & Stage III & 14 & $\mathrm{BSO}$ & 4 \\
\hline$P S=0$ & 6 & Ovary - mucinous & I & Stage IV & 6 & $\mathrm{BSO}$ and omentectomy & 2 \\
\hline$P S=1$ & || & Primary peritoneal - serous & 1 & & & RSO and omentectomy & । \\
\hline$P S=2$ & 3 & Primary peritoneal - clear cell & i & & & Biopsy only & 2 \\
\hline$P S=3$ & । & Fallopian tube - endometroid & I & & & & \\
\hline
\end{tabular}

$\mathrm{TAH}=$ total abdominal hysterectomy; $\mathrm{BSO}=$ bilateral salpingo-oophorectormy. 
Table 4 Toxicity data

Dose-limiting toxicity (following cycle I only)

\begin{tabular}{|c|c|c|c|c|}
\hline Dose level & Number of patients (n) & Thrombocytopenia & Neutropenia & Sepsis \\
\hline Ia $(1.0 / 2.0)$ & 2 & | & 2 & 2 \\
\hline Ib $(0.85 / 2.0)$ & 3 & i & 3 & 3 \\
\hline $2 \mathrm{a}(0.85 / 1.0)$ & $1 \mid$ & 0 & 4 & 1 \\
\hline $2 b(0.85 / 1.5)$ & 5 & 4 & 4 & 4 \\
\hline
\end{tabular}

Haematological toxicity over 6 cycles

\begin{tabular}{lcccc}
\hline Dose level & n & Anaemia & Thrombocytopenia & Neutropenia \\
\hline Ia $(1.0 / 2.0)$ & 2 & 0 & 1 & 2 \\
Ib $(0.85 / 2.0)$ & 3 & 0 & 2 & 3 \\
2a $(0.85 / 1.0)$ & $1 \mid$ & 2 & 3 & 6 \\
2b $(0.85 / 1.5)$ & 5 & 0 & 4 & 5
\end{tabular}

Nonhaematological toxicity over 6 cycles

\begin{tabular}{|c|c|c|c|c|c|}
\hline Dose level & $n$ & Alopecia grade $\leqslant 2$ & Nausea grade $=3$ & Stomatitis grades $2-3$ & Diarrhoea grades 2-3 \\
\hline Ia $(1.0 / 2.0)$ & 2 & 2 & 0 & 2 & I \\
\hline Ib $(0.85 / 2.0)$ & 3 & 2 & I & 2 & I \\
\hline $2 \mathrm{a}(0.85 / 1.0)$ & | | & | | & 2 & 2 & 0 \\
\hline $2 b(0.85 / 1.5)$ & 5 & 5 & 0 & I & 0 \\
\hline
\end{tabular}

Only grade 4 haematological toxicity presented.
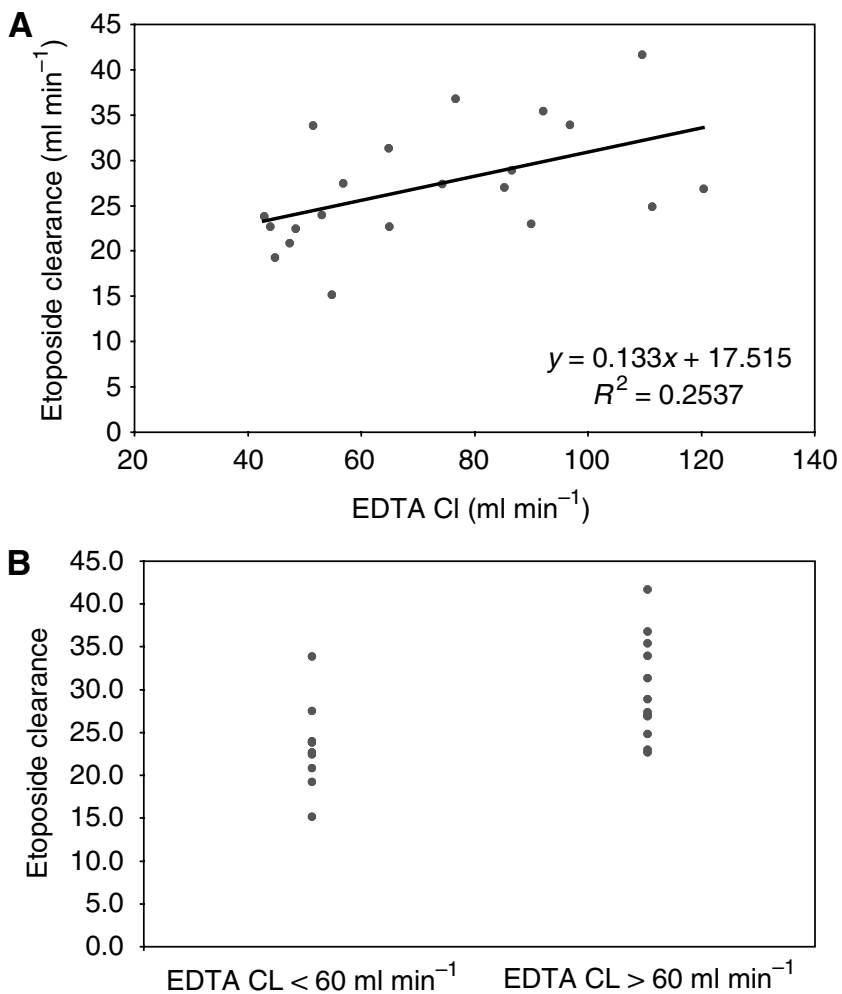

Figure I Etoposide clearance. Relationship between etoposide clearance and EDTA clearance (renal function) prior to treatment, shown as a regression curve $(\mathbf{A})$ and as a scatter graph for EDTA clearance below and above $60 \mathrm{ml} \mathrm{min}^{-1}$ (B).

responses were demonstrated in 28\% (five out of 18) of patients at completion of treatment (Table 6). All responding patients had been sensitive to platinum first line and four out of five had also been treated previously with paclitaxel. All of the 18 evaluable patients had an elevated Ca125 level at the start of the trial. Six patients had $a \geqslant 50 \%$ fall in their level, and in a further five patients the Ca125 levels fell below baseline but by less than $50 \%$ after six cycles. Of the 21 patients, 11 went onto between 1 and 3 (mean 1.5) further regimens of chemotherapy, after completion of chemotherapy in this study. The median survival for patients was 11.7 months from the start of treatment on this study, with all patients having died at the time of this report.

\section{Quality of life}

Quality of life was measured during the treatment using the EORTC QL-30 questionnaire (Figure 3). Quality of life was statistically related to patients' haemoglobin level and to their level of symptoms. There was a trend for QOL to improve during the trial; however, the difference was not statistically significant.

\section{Preclinical studies}

Apoptosis was assessed following exposure to etoposide and $\mathrm{SN}-38$ in combination (Figure $4 \mathrm{~A}-\mathrm{C}$ ). With the exception of $\mathrm{SN}-38$ in A2780 cells, where the response was mainly cell cycle arrest even up to $100 \mathrm{ng} \mathrm{ml}^{-1}, \mathrm{SN}-38$ drug concentrations used were those that resulted in approximately $10 \%$ apoptosis after a 3 -day exposure. The percentage of apoptotic cells in each experiment was determined by flow cytometry using propidium iodide staining of DNA on the last day of each treatment.

For each cell line, exposure to both drugs simultaneously resulted in less apoptosis than would be expected from the additive effect of each drug given separately. Schedules in which the agents were used consecutively were consistently more active than those involving concurrent exposure, even though the overall exposure (concentration $\times$ time) for both agents was the same in each schedule. The most active combination overall, as evaluated by induction of apoptosis, was $\mathrm{SN}-38$ for 3 days, followed by 1 day drug free and then etoposide for a further 3 days in all cell lines (Figure 4A-C). 


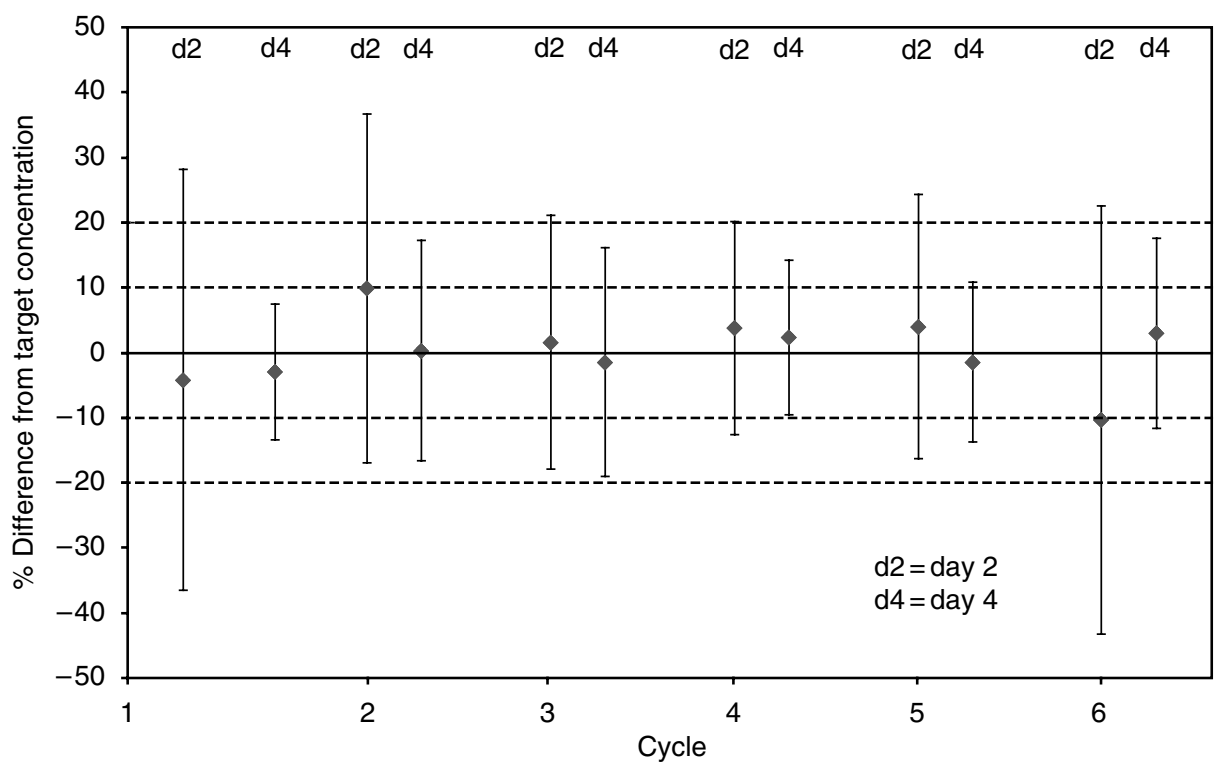

Figure 2 Difference from target concentration. Graph demonstrating the variability of plasma etoposide concentrations, measured on days 2 and 4 of the infusion, for each cycle.

Table 5 Patients requiring dose adjustments of etoposide phosphate following measured etoposide levels more or less than 10\% from the target level

\begin{tabular}{lcccc}
\hline Cycle & $\begin{array}{c}\text { No. of } \\
\text { patients } \\
\text { treated }\end{array}$ & $\begin{array}{c}\text { No. of } \\
\text { patients for } \\
\text { whom data } \\
\text { available }\end{array}$ & $\begin{array}{c}\text { Patients } \\
\text { requiring dose } \\
\text { adjustment on } \\
\text { day 2 }\end{array}$ & $\begin{array}{c}\text { Patients } \\
\text { requiring dose } \\
\text { adjustment on } \\
\text { day 4 }\end{array}$ \\
\hline 1 & 21 & 21 & 18 & 4 \\
2 & 21 & 19 & 15 & 8 \\
3 & 18 & 18 & 12 & 8 \\
4 & 14 & 13 & 6 & 6 \\
5 & 14 & 14 & 12 & 4 \\
6 & 12 & 12 & 7 & 7 \\
\hline
\end{tabular}

Table 6 Response data for evaluable patients ( $\geqslant 3$ cycles of treatment)

Response to treatment

\begin{tabular}{lcccccc} 
Dose level & $\mathbf{n}$ & PR & SD & PD & $\begin{array}{c}\text { Platinum } \\
\text { resistant }\end{array}$ & $\begin{array}{c}\text { Previous } \\
\text { paclitaxel }\end{array}$ \\
\hline Ia $(1.0 / 2.0)$ & 2 & 2 & 0 & 0 & 0 & 2 \\
Ib $(0.85 / 2.0)$ & 3 & 0 & 1 & 2 & 2 & 3 \\
2a $(0.85 / 1.0)$ & 9 & 2 & 3 & 4 & 4 & 5 \\
2b $(0.85 / 1 / 5)$ & 4 & 1 & 2 & 1 & 1 & 4 \\
Total & 18 & 5 & 6 & 7 & 7 & 14 \\
\hline
\end{tabular}

$\mathrm{PR}=$ partial remission; $\mathrm{SD}=$ stable disease; $\mathrm{PD}=$ progressive disease.

\section{Topoisomerase II $\alpha$ levels}

The topoisomerase II $\alpha$ levels were not increased in peripheral lymphocytes after topotecan treatment (Figure 5). The topoisomerase II $\alpha$ levels in 10 patients showed a mean reduction of 2.14 arbitrary units $(P=0.02)$ following topotecan, compared to baseline measurements. However, there was no trend for change overall with treatment for all patients or for the subset of those who responded to treatment.

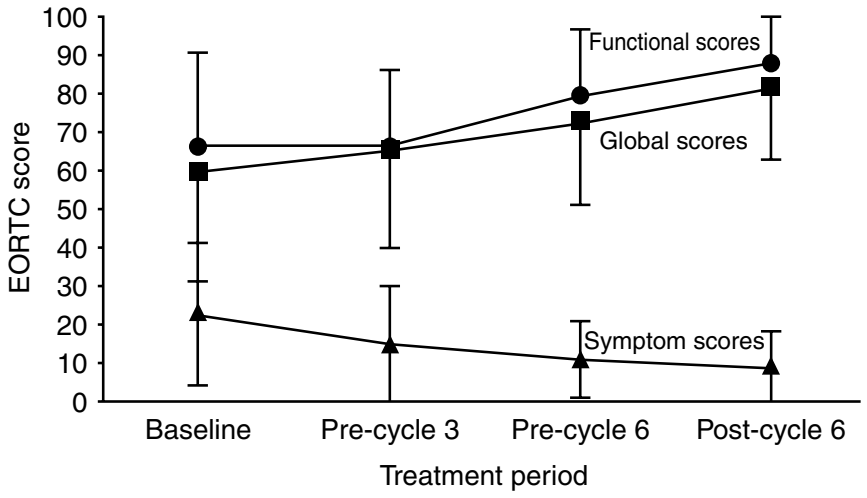

Figure 3 European Organisation for Research and Treatment of Cancer (EORTC) score. Mean EORTC QOL scores ( \pm | s.d.) calculated at baseline, before cycles 3 and 6 and after cycle 6 .

\section{DISCUSSION}

One of the goals of combination chemotherapy is the development of regimens with synergistic activity and noncrossover toxicity. This paper explores the combination of topotecan and EP; from preclinical studies to suggest the most active sequencing of the drugs, through to a phase I study of the combination in patients with advanced ovarian cancer.

Release of tortional stress in supercoiled DNA is necessary prior to replication and cell division. Topoisomerase I induces a singlestrand break in DNA, allowing it to unwind, before repair of the break. Topotecan binds and stabilises the topoisomerase I-DNA complex, preventing resealing of the DNA (Hsiang et al, 1985). This leads to double-strand breaks, apoptosis and cell death.

Type II topoisomerases make transient breaks in doublestranded DNA (dsDNA). Etoposide binds and stabilises an intermediate enzyme-DNA structure inhibiting further enzyme activity (Chen and Liu, 1994; Froelich-Ammon and Osheroff, 1995). When the cell attempts to replicate its DNA, these complexes are disrupted causing double-strand breaks, which, 

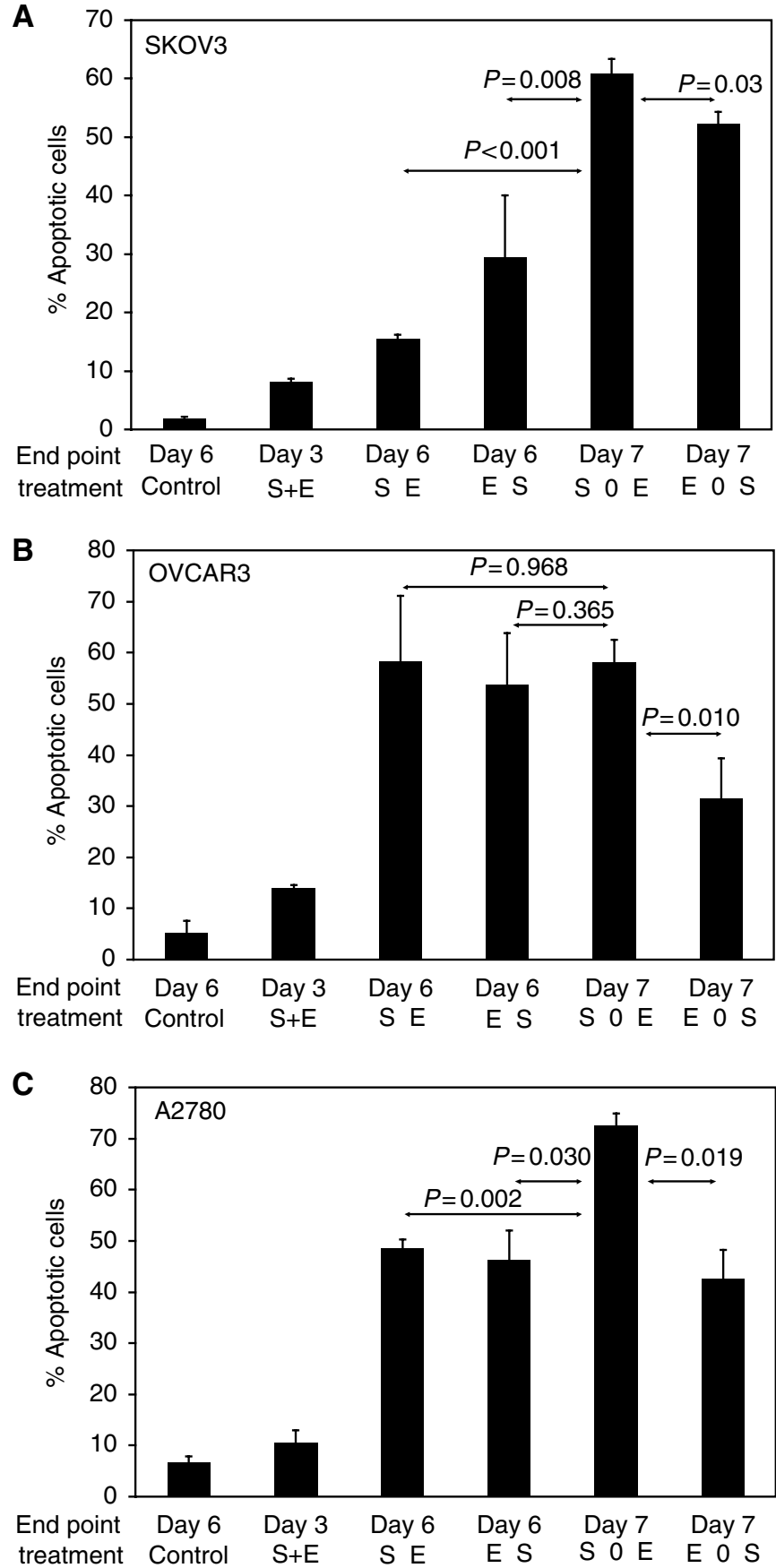

Figure 4 Percentage of apoptotic cells. Apoptosis (mean + s.d.) induced by combinations of etoposide and SN-38 in SKOV-3 (A), OVCAR-3 (B) and A2780 (C) ovarian cancer cell lines. The treatments were; Control, SN-38 + etoposide concurrently for 3 days $(\mathrm{S}+\mathrm{E}), \mathrm{SN}-38$ for days I - 3 immediately followed by etoposide for days 3-6 (SE), etoposide for days I -3 immediately followed by SN-38 for days 3-6 (ES), SN-38 for days I-3 followed by I day drug free, then etoposide for days 4-7 (SOE), etoposide for days I -3 followed by I day drug free, then SN-38 for days 4-7 (EOS).

unless repaired, will be lethal to the cell. Thus, etoposide cytotoxicity depends both on the level of topoisomerase II, which is expressed only in dividing cells in the later phases of the cell cycle (Heck et al, 1988), and secondly on duration of exposure of cells to the drug.
The in vitro studies described here demonstrate the schedule dependence underlying the interaction between topoisomerase I and II inhibitors ( $\mathrm{SN}-38$ was used for in vitro experiments as it is also a topoisomerase I inhibitor). These data also demonstrate antagonism when the two agents were used simultaneously, where the expected effect ( $20 \%$ apoptosis) based on the activity of each agent used alone was not observed in any cell line. Increased activity, inducing the greatest percentage of apoptotic cells, was observed with schedules in which the two drugs were given sequentially. The most active combination overall was $\mathrm{SN}-38$ for 3 days, followed by 1 day without drug treatment, and then etoposide for a further 3 days. Cell cycle data (not shown) suggested that the increased apoptotic effect observed with consecutive exposures may be due to relief of the cell cycle block occurring after exposure to the first agent, when that agent is removed and the cells are then exposed to the second agent. This is more marked when the drug-free interval is short. These results led to the adoption of a similar schedule for the clinical trial.

These results are in keeping with previous in vitro studies demonstrating synergy when topotecan is followed by etoposide (Bonner and Kozelsky, 1996; Grabowski and Ganapathi, 1996; Chen et al, 2002). Synergy has also been demonstrated in human xenograft mouse tumour models (Kim et al, 1992; Whitacre et al, 1997). Additive effects have also been observed when topoisomerase I and II inhibitors were given sequentially as opposed to simultaneously (Bertrand et al, 1992). By contrast, simultaneous incubation of cells with camptothecin (a topoisomerase I inhibitor) and etoposide has shown reduced cytotoxicity compared to etoposide given alone (Kaufmann, 1991).

The preclinical data presented here suggested synergistic activity when cells are treated sequentially with topoisomerase I then II inhibition. The topoisomerase 'shutdown' model predicts that treatment of cells with a topoisomerase I inhibitor results in upregulation of topoisomerase II levels, as an alternative DNA repair mechanism is activated. Sequential treatment with a topoisomerase II inhibitor, where the activity is in part dependent on topoisomerase II levels is therefore predicted to be synergistic. However, in a study in patients with advanced non-SCLC, of topotecan $0.85 \mathrm{mg} \mathrm{m}^{-2}$ day $^{-1}$ as a continuous i.v. infusion for $24 \mathrm{~h}$ followed by oral etoposide $100 \mathrm{mg}$ b.i.d. on days 7-9, only one patient responded to treatment and the authors concluded that in future studies etoposide should be given more closely following the topotecan (Dowlati et al, 2001). Etoposide phosphate infusions allow prolonged scheduling of etoposide with pharmacokinetic monitoring to allow dose adjustments. Trials in our unit over the past decade have shown this to be feasible and well tolerated (O’Byrne et al, 1997; Joel et al, 1998; Braybrooke et al, 2003). Experience from previous studies, together with the preclinical data presented here, led to the adoption of the sequential administration of topotecan for 5 days followed by EP for 5 days as a novel regimen to be investigated in this phase I study in patients with advanced ovarian cancer. As anticipated, the major toxicity of topotecan followed by EP was myelosuppression. The MTD was topotecan $0.85 \mathrm{mg} \mathrm{m}^{-2}$ day $^{-1}$ followed immediately by a 5-day infusion of EP at a plasma concentration of $1 \mu \mathrm{g} \mathrm{ml}^{-1}$. However, seven out of 11 patients on this dose level completed six cycles, in keeping with this dose level being a feasible dose for further study in a phase II trial. Two commonly used second-line treatments for ovarian cancer are single agent topotecan $1.5 \mathrm{mg} \mathrm{m}^{-2}$ day $^{-1}$ days $1-5 \mathrm{q}^{2} 1$ and liposomal doxorubicin $50 \mathrm{mg} \mathrm{m}^{-2} \mathrm{q} 28$. These schedules have been compared head to head in a phase III study (Gordon et al, 2001). Table 7 compares the toxicities observed in the Gordon study with those from this study at the dose level suggested for phase II evaluation. The haematological toxicities from this study and the single agent topotecan arm are similar, especially given the use of stem cell growth factor support in the Gordon study. This strengthens the 
A

3

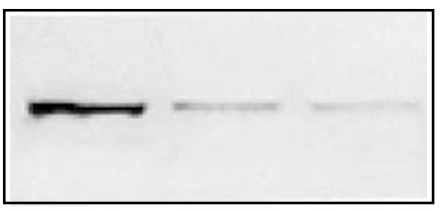

Topoisomerase Il $\alpha$

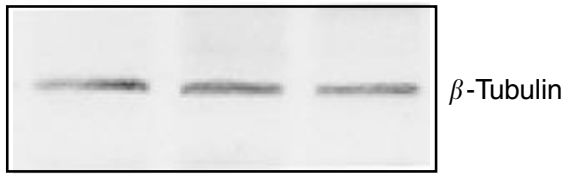

B

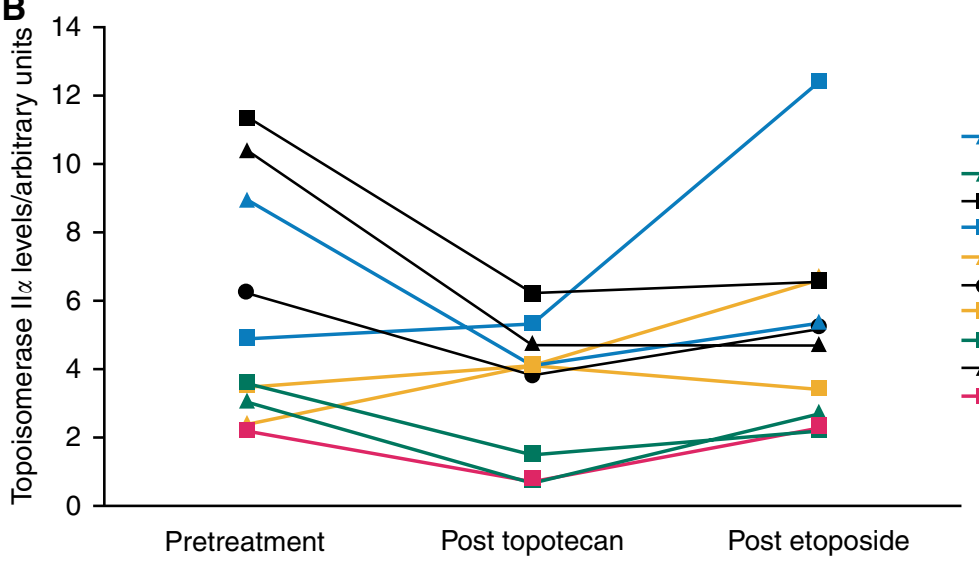

Individual

patient data

Figure 5 Topoisomerase $\| \alpha$ levels/arbitrary units. Topoisomerase $\| \alpha$ levels in peripheral blood. An example Western blot of topoisomerase $\| \alpha(\mathbf{A})$. Lymphopreps were made from peripheral blood samples taken pretreatment (1), post-topotecan (2) and post-etoposide (3) administration. Western blotting was performed on proteins from the lymphocyte cell pellet. Blots were probed with a monoclonal anti-topoisomerase ll $\alpha$ antibody. $\beta$ Tubulin was used as a loading control. Scatter graph of topoisomerase Il $\alpha$ levels in peripheral lymphocytes for all 10 patients at baseline, after topotecan and at the end of treatment $(\mathbf{B})$.

Table 7 Comparison of percentage of patients with grade 3/4 toxicities with that of Gordon et al (200 I)

\begin{tabular}{|c|c|c|c|}
\hline & $\begin{array}{c}\text { Topotecan } \\
\left(0.85 \mathrm{mg} \mathrm{m}^{2} \text { day }^{-1}\right. \\
\text { days } \mathrm{I}-5 \text {, EP } \\
\left(1 \mu \mathrm{gl}^{-1}\right) \text { days } \\
6-10\end{array}$ & $\begin{array}{c}\text { Topotecan } \\
\left(\begin{array}{c}\left.1.5 \mathrm{mg} \mathrm{m}^{2} \text { day }^{-1}\right) \\
\text { days I -5 q2 I }\end{array}\right.\end{array}$ & $\begin{array}{c}\text { Liposomal } \\
\text { doxorubicin } \\
\left(50 \mathrm{mg} \mathrm{m}^{-2}\right) \\
\text { q28 }\end{array}$ \\
\hline Neutropenia $^{\mathrm{a}}$ & 82 & 77 & 12 \\
\hline Anaemia & 45 & 28 & 5 \\
\hline Thrombocytopenia & 45 & 34 & I \\
\hline $\begin{array}{l}\text { Plantar/palmer } \\
\text { erythema }\end{array}$ & 0 & 0 & 23 \\
\hline Stomatitis & 0 & 0.4 & 8 \\
\hline
\end{tabular}

${ }^{a}$ Growth factor support was used in the study of Gordon et al (200I).

case further for the use of topotecan/EP as reasonable for a palliative regimen.

The combination of topotecan followed by etoposide has been evaluated in other studies. In patients with AML (acute myeloid leukaemia), an MTD of topotecan $1.5 \mathrm{mg} \mathrm{m}^{-2} \mathrm{day}^{-1}$ continuous infusion days $1-5$ followed by etoposide $100 \mathrm{mg} \mathrm{m}^{-2}$ day $^{-1} \times 3$ was identified (Crump et al, 1999). Mucositis was the DLT with grade 4 neutropenia and thrombocytopenia also observed. Other disease-specific phase I studies of sequential topotecan and etoposide have also found myelosuppression to be dose limiting (Cooper et al, 1996; Herben et al, 1997; Hammond et al, 1998; Crump et al, 2002). However, a phase I study in SCLC found topotecan $0.75 \mathrm{mg} \mathrm{m}^{-2} \mathrm{day}^{-1}$ followed by a 1 -h infusion of etoposide $60 \mathrm{mg} \mathrm{m}^{-2}$ day $^{-1}$ daily for 5 days in a three weekly cycle was well tolerated (O'Neill et al, 2001). Two studies have examined the effect of order of sequential topotecan and etoposide in patients with lung cancer. Patients received the two drugs in the opposite order in subsequent cycles. No difference in toxicity was observed between the different sequences and in both studies, myelotoxicity was dose limiting (Huisman et al, 2001; Mok et al, 2002).

The response rate in this study was $28 \%$ in evaluable patients, of whom half were resistant to platinum. This compares favourably with the response rate of $20.5 \%$ for topotecan given second line in advanced ovarian cancer (ten Bokkel Huinink et al, 1997). All responding patients had been sensitive to platinum first line. Five of the six responding patients had also been treated previously with paclitaxel, supporting the data that the combination of topotecan and etoposide is noncrossresistant with paclitaxel. Of 18 patients, 12 were evaluable by Ca125 and had a decrease or stabilisation of their levels. Although this has not been shown to correlate with activity, it may be that more minor improvements in disease parameters are clinically relevant in the setting of advanced disease, where prolonged stabilisation is a valid clinical objective. The QOL data showed a trend to improvement during the course of the study. Quality of life scores were statistically related to haemoglobin concentration, as previously described (Littlewood et al, 2001).

There are two human type II topoisomerases, $\alpha$ and $\beta$. Topoisomerase II $\alpha$ levels vary with the cell cycle (unlike topoisomerase $\operatorname{II} \beta$ ) and are not detectable in S-phase but increase through the cell cycle, peaking at $\mathrm{G}_{2} / \mathrm{M}$ (Woessner et al, 1991). An 
in vitro study demonstrated that topoisomerase II $\alpha$ levels could be induced in colon cancer cell xenografts that had been exposed to topotecan. However, if topotecan treatment was withdrawn for 5 days, the topoisomerase II $\alpha$ level fell back to baseline (Whitacre et al, 1997). This further supports that etoposide should administered immediately follow topotecan, as in this study.

Topoisomerase II $\alpha$ levels measured during this study did not show any significant changes from baseline to the end of treatment with topoisomerase I then II inhibition, although there was a trend for topoisomerase II $\alpha$ levels to fall following topotecan (Figure 5B). However, the topoisomerase II $\alpha$ were measured in circulating lymphocytes, which are not undergoing cell division. Only cycling cells are expected to have high levels of topoisomerase II $\alpha$ and to be sensitive to topotecan and this may account for our findings in peripheral blood.

Topoisomerase II $\alpha$ levels measured in the tumour cell lines did rise following $\mathrm{SN}-38$ and fell again following etoposide, as predicted in the topoisomerase 'shutdown' model (data not shown). Similar results have been demonstrated in CML K562 cells treated with topoisomerase I then II inhibitors (Chen et al, 2002). A rise in topoisomerase II $\alpha$ has also been observed in peripheral blast cells from leukaemia patients by day 3 of treatment with topotecan, although levels returned to baseline by day 5 (Crump et al, 1999). In another study in leukaemia patients treated with topotecan then etoposide and mitoxantrone, a rise in topoisomerase II $\alpha$ post topotecan correlated with response to treatment (Mainwaring et al, 2002). A further study using fluorescence cytometry to measure nuclear topoisomerase II $\alpha$ levels in cells from patients with AML also showed a rise in the median value after $48 \mathrm{~h}$ of treatment with topotecan, falling again by 5 days, although marked interpatient variability was observed (Nicklee et al, 1996). Topoisomerase II $\alpha$ levels have also been measured in tumour biopsy specimens, pre and post topotecan and etoposide treatment, in four patients as part of a phase I study. There was no convincing pattern of change, in particular three out of four patients' levels were unchanged following topotecan

\section{REFERENCES}

Ausubel F, Brent R, Kingston R, Moore D, Seidman J, Smith J, Struhl K (1994) Current Protocols In Molecular Biology. New York: John Wiley \& Sons

Bertrand R, O'Connor PM, Kerrigan D, Pommier Y (1992) Sequential administration of camptothecin and etoposide circumvents the antagonistic cytotoxicity of simultaneous drug administration in slowly growing human colon carcinoma HT-29 cells. Eur J Cancer 28: $743-748$

Bonner JA, Kozelsky TF (1996) The significance of the sequence of administration of topotecan and etoposide. Cancer Chemother Pharmacol 39: $109-112$

Bookman MA, Malmstrom H, Bolis G, Gordon A, Lissoni A, Krebs JB, Fields SZ (1998) Topotecan for the treatment of advanced epithelial ovarian cancer: an open-label phase II study in patients treated after prior chemotherapy that contained cisplatin or carboplatin and paclitaxel. J Clin Oncol 16: $3345-3352$

Braybrooke JP, Levitt NC, Joel S, Davis T, Madhusudan S, Turley H, Wilner S, Harris AL, Talbot DC (2003) Pharmacokinetic study of cisplatin and infusional etoposide phosphate in advanced breast cancer with correlation of response to topoisomerase IIalpha expression. Clin Cancer Res 9: $4682-4688$

Chen AY, Liu LF (1994) DNA topoisomerases: essential enzymes and lethal targets. Annu Rev Pharmacol Toxicol 34: 191-218

Chen S, Gomez SP, McCarley D, Mainwaring MG (2002) Topotecaninduced topoisomerase IIalpha expression increases the sensitivity of the CML cell line K562 to subsequent etoposide plus mitoxantrone treatment. Cancer Chemother Pharmacol 49: 347-355

Cooper B, Lazarus H, Creger R, Willson JK, Hoppel CL, Berger SJ, Berger NA, Gosky DM, McGloin B, Gerson SL (1996) A phase I and pharmacodynamic study of sequential topotecan and etoposide (TE) in administration; however, these numbers are very small (Hammond et al, 1998).

Separately, topotecan at $1.5 \mathrm{mg} \mathrm{m}^{-2} \mathrm{day}^{-1}$ and EP at a plasma etoposide concentration of $3 \mu \mathrm{g} \mathrm{ml}^{-1}$, each over 5 days, can be given with very manageable toxicity. In this study, substantially lower doses of both topotecan and etoposide given sequentially resulted in greater than anticipated haematological toxicity. Furthermore, there was a higher tumour response rate $(28 \%$ in evaluable patients, $24 \%$ if all 21 patients were included) than would be expected for the combination of drugs at these subtherapeutic doses. Together with the preclinical data, the toxicity and response rate from this study argue for synergy of action between these drugs.

A shorter course of topotecan $1.5 \mathrm{mg} \mathrm{m}^{-2}$ day $^{-1}$ for 3 days, $\mathrm{q} 21$ in platinum and paclitaxel-refractory ovarian cancer has been investigated (Markman et al, 2000) and the 3-day topotecan programme was found to be more convenient and less toxic than the standard 5-day regimen with apparently comparable activity. From this study, the recommended dose for a phase II trial is topotecan $0.85 \mathrm{mg} \mathrm{m}^{-2}$ day $^{-1}$ for 5 days followed immediately by a 5-day infusion of EP at a plasma concentration of $1 \mu \mathrm{g} \mathrm{ml}^{-1}$. However, in view of the considerable haematological toxicity in this study and the results from Markman's study (Markman et al, 2000), a 3-day topotecan $0.85 \mathrm{mg} \mathrm{m}^{-2}$ day $^{-1}$ schedule followed by a 5-day infusion of EP at $1 \mu \mathrm{g} \mathrm{ml}^{-1}$ might be preferable. In future studies, it would be of particular interest to measure topoisomerase II $\alpha$ levels in cycling cells, either from tumour biopsy specimens or in cells collected from patients with ascites.

\section{ACKNOWLEDGEMENTS}

We acknowledge the support of Smith-Kline Beecham for provision of drug. We are grateful for patients for consenting to participate in the study. Cancer Research UK supported the study. adult patients with refractory relapsed acute leukemia (RAL). Proc Am Soc Clin Oncol 15: 486

Creemers GJ, Bolis G, Gore M, Scarfone G, Lacave AJ, Guastalla JP, Despax R, Favalli G, Kreinberg R, Van Belle S, Hudson I, Verweij J, Ten Bokkel Huinink WW (1996) Topotecan, an active drug in the second-line treatment of epithelial ovarian cancer: results of a large European phase II study. J Clin Oncol 14: 3056-3061

Crump M, Couban S, Meyer R, Rudinskas L, Zanke B, Gluck S, Maksymiuk A, Hoskins P, Matthews S, Eisenhauer E (2002) Phase II study of sequential topotecan and etoposide in patients with intermediate grade non-Hodgkin's lymphoma: a National Cancer Institute of Canada Clinical Trials Group study. Leuk Lymphoma 43: 1581 - 1587

Crump M, Lipton J, Hedley D, Sutton D, Shepherd F, Minden M, Stewart K, Beare S, Eisenhauer E (1999) Phase I trial of sequential topotecan followed by etoposide in adults with myeloid leukemia: a National Cancer Institute of Canada Clinical Trials Group Study. Leukemia 13: 343-347

Dowlati A, Levitan N, Gordon NH, Hoppel CL, Gosky DM, Remick SC, Ingalls ST, Berger SJ, Berger NA (2001) Phase II and pharmacokinetic/ pharmacodynamic trial of sequential topoisomerase I and II inhibition with topotecan and etoposide in advanced non-small-cell lung cancer. Cancer Chemother Pharmacol 47: 141-148

Froelich-Ammon SJ, Osheroff N (1995) Topoisomerase poisons: harnessing the dark side of enzyme mechanism. J Biol Chem 270: 21429-21432

Gordon AN, Fleagle JT, Guthrie D, Parkin DE, Gore ME, Lacave AJ (2001) Recurrent epithelial ovarian carcinoma: a randomized phase III study of pegylated liposomal doxorubicin versus topotecan. J Clin Oncol 19: $3312-3322$

Gore M, ten Bokkel Huinink W, Carmichael J, Gordon A, Davidson N, Coleman R, Spaczynski M, Heron JF, Bolis G, Malmstrom H, Malfetano J, Scarabelli C, Vennin P, Ross G, Fields SZ (2001) Clinical evidence for 
topotecan-paclitaxel non-cross-resistance in ovarian cancer. J Clin Oncol 19: $1893-1900$

Grabowski D, Ganapathi R (1996) Cytotoxic efficacy with combinations of topoisomerase I and topoisomerase II inhibitors in sensitive and multidrug-resistant L1210 mouse leukemia cells. Ann N Y Acad Sci 803: $306-307$

Hainsworth JD, Johnson DH, Frazier SR, Greco FA (1989) Chronic daily administration of oral etoposide - a phase I trial. J Clin Oncol 7: 396-401

Hammond LA, Eckardt JR, Ganapathi R, Burris HA, Rodriguez GA, Eckhardt SG, Rothenberg ML, Weiss GR, Kuhn JG, Hodges S, Von Hoff DD, Rowinsky EK (1998) A phase I and translational study of sequential administration of the topoisomerase I and II inhibitors topotecan and etoposide. Clin Cancer Res 4: 1459-1467

Hande KR (1998) Etoposide: four decades of development of a topoisomerase II inhibitor. Eur J Cancer 34: 1514-1521

Harvey VJ, Joel SP, Johnston A, Slevin ML (1985a) High-performance liquid chromatography of etoposide in plasma and urine. J Chromatogr 339: $419-423$

Harvey VJ, Slevin ML, Joel SP, Smythe MM, Johnston A, Wrigley PF (1985b) Variable bioavailability following repeated oral doses of etoposide. Eur I Cancer Clin Oncol 21: 1315-1319

Heck MM, Hittelman WN, Earnshaw WC (1988) Differential expression of DNA topoisomerases I and II during the eukaryotic cell cycle. Proc Natl Acad Sci USA 85: 1086-1090

Herben VM, ten Bokkel Huinink WW, Dubbelman AC, Mandjes IA, Groot Y, van Gortel-van Zomeren DM, Beijnen JH (1997) Phase I and pharmacological study of sequential intravenous topotecan and oral etoposide. $\mathrm{Br}$ J Cancer 76: $1500-1508$

Hoskins PJ, Swenerton KD (1994) Oral etoposide is active against platinumresistant epithelial ovarian cancer. I Clin Oncol 12: 60-63

Hsiang YH, Hertzberg R, Hecht S, Liu LF (1985) Camptothecin induces protein-linked DNA breaks via mammalian DNA topoisomerase I. J Biol Chem 260: 14873 - 14878

Huisman C, Postmus PE, Giaccone G, Smit EF (2001) A phase I study of sequential intravenous topotecan and etoposide in lung cancer patients. Ann Oncol 12: $1567-1573$

ICON3 collaborators (2002) Paclitaxel plus carboplatin versus standard chemotherapy with either single-agent carboplatin or cyclophosphamide, doxorubicin, and cisplatin in women with ovarian cancer: the ICON3 randomised trial. Lancet 360: $505-515$

Joel SP, Ellis P, O’Byrne K, Papamichael D, Hall M, Penson R, Nicholls S, O'Donnell C, Constantinou A, Woodhull J, Nicholson M, Smith I, Talbot D, Slevin M (1996) Therapeutic monitoring of continuous infusion etoposide in small-cell lung cancer. J Clin Oncol 14: $1903-1912$

Joel SP, O’Byrne K, Penson R, Papamichael D, Higgins A, Robertshaw H, Rudd R, Talbot D, Slevin M (1998) A randomised, concentrationcontrolled, comparison of standard (5-day) vs prolonged (15-day) infusions of etoposide phosphate in small-cell lung cancer. Ann Oncol 9: $1205-1211$

Kaufmann SH (1991) Antagonism between camptothecin and topoisomerase II-directed chemotherapeutic agents in a human leukemia cell line. Cancer Res 51: 1129-1136

Kim R, Hirabayashi N, Nishiyama M, Jinushi K, Toge T, Okada K (1992) Experimental studies on biochemical modulation targeting topoisomerase I and II in human tumor xenografts in nude mice. Int J Cancer 50: $760-766$

Kudelka AP, Tresukosol D, Edwards CL, Freedman RS, Levenback C, Chantarawiroj P, Gonzalez de Leon C, Kim EE, Madden T, Wallin B, Hord M, Verschraegen C, Raber M, Kavanagh JJ (1996) Phase II study of intravenous topotecan as a 5-day infusion for refractory epithelial ovarian carcinoma. J Clin Oncol 14: 1552-1557

Littlewood TJ, Bajetta E, Nortier JW, Vercammen E, Rapoport B (2001) Effects of epoetin alfa on hematologic parameters and quality of life in cancer patients receiving nonplatinum chemotherapy: results of a randomized, double-blind, placebo-controlled trial. J Clin Oncol 19: $2865-2874$

Mainwaring MG, Rimsza LM, Chen SF, Gomez SP, Weeks FW, Reddy V, Lynch J, May WS, Kahn S, Moreb J, Leather H, Braylan R, Rowe TC, Fieniewicz KJ, Wingard JR (2002) Treatment of refractory acute leukemia with timed sequential chemotherapy using topotecan followed by etoposide+mitoxantrone (T-EM) and correlation with topoisomerase II levels. Leuk Lymphoma 43: 989-999

Markman M, Kennedy A, Webster K, Kulp B, Peterson G, Belinson J (2000) Phase 2 evaluation of topotecan administered on a 3-day schedule in the treatment of platinum- and paclitaxel-refractory ovarian cancer. Gynecol Oncol 79: $116-119$

McGuire WP, Hoskins WJ, Brady MF, Kucera PR, Partridge EE, Look KY, Clarke-Pearson DL, Davidson M (1996) Cyclophosphamide and cisplatin versus paclitaxel and cisplatin: a phase III randomized trial in patients with suboptimal stage III/IV ovarian cancer (from the Gynecologic Oncology Group). Semin Oncol 23: 40-47

Mok TS, Wong H, Zee B, Yu KH, Leung TW, Lee TW, Yim A, Chan AT, Yeo W, Chak K, Johnson P (2002) A Phase I-II study of sequential administration of topotecan and oral etoposide (toposiomerase I and II inhibitors) in the treatment of patients with small cell lung carcinoma. Cancer 95: 1511 - 1519

Muggia FM, Braly PS, Brady MF, Sutton G, Niemann TH, Lentz SL, Alvarez RD, Kucera PR, Small JM (2000) Phase III randomized study of cisplatin versus paclitaxel versus cisplatin and paclitaxel in patients with suboptimal stage III or IV ovarian cancer: a gynecologic oncology group study. J Clin Oncol 18: $106-115$

Negri C, Chiesa R, Cerino A, Bestagno M, Sala C, Zini N, Maraldi NM, Astaldi Ricotti GC (1992) Monoclonal antibodies to human DNA topoisomerase I and the two isoforms of DNA topoisomerase II: 170and 180-kDa isozymes. Exp Cell Res 200: 452-459

Nicklee T, Crump M, Hedley DW (1996) Effects of topoisomerase I inhibition on the expression of topoisomerase II alpha measured with fluorescence image cytometry. Cytometry 25: 205-210

O’Byrne KJ, Joel S, Jeffrey B, Propper D, Brayebrooke J, Sanders A, Elliott M, Taylor M, Slevin M, Ganesan TS (1997) Pharmacokinetically doseadjusted infusion of etoposide phosphate in recurrent ovarian cancer. Proc Am Soc Clin Oncol 16: 375

O’Neill P, Clark PI, Smith D, Marshall E, Hannigan K, Ross G (2001) A phase I trial of a 5-day schedule of intravenous topotecan and etoposide in previously untreated patients with small-cell lung cancer. Oncology 61(Suppl 1): $25-29$

Piccart MJ, Bertelsen K, James K, Cassidy J, Mangioni C, Simonsen E, Stuart G, Kaye S, Vergote I, Blom R, Grimshaw R, Atkinson RJ, Swenerton KD, Trope C, Nardi M, Kaern J, Tumolo S, Timmers P, Roy JA, Lhoas F, Lindvall B, Bacon M, Birt A, Andersen JE, Zee B, Paul J, Baron B, Pecorelli S (2000) Randomized intergroup trial of cisplatin-paclitaxel versus cisplatin-cyclophosphamide in women with advanced epithelial ovarian cancer: three-year results. J Natl Cancer Inst 92: 699-708

Rose PG, Blessing JA, Mayer AR, Homesley HD (1998) Prolonged oral etoposide as second-line therapy for platinum-resistant and platinumsensitive ovarian carcinoma: a Gynecologic Oncology Group study. J Clin Oncol 16: $405-410$

Rowinsky EK, Verweij J (1997) Review of phase I clinical studies with topotecan. Semin Oncol 24: S20-3-S20-10

Seymour MT, Mansi JL, Gallagher CJ, Gore ME, Harper PG, Evans TR, Edmonds PM, Slevin ML (1994) Protracted oral etoposide in epithelial ovarian cancer: a phase II study in patients with relapsed or platinumresistant disease. Br J Cancer 69: $191-195$

Slevin ML, Joel SP (1993) Prolonged oral etoposide in small cell lung cancer. Ann Oncol 4: 529-532

Stuart GC (2003) First-line treatment regimens and the role of consolidation therapy in advanced ovarian cancer. Gynecol Oncol 90: S8-S15

ten Bokkel Huinink W, Gore M, Carmichael J, Gordon A, Malfetano J, Hudson I, Broom C, Scarabelli C, Davidson N, Spanczynski M, Bolis G, Malmstrom H, Coleman R, Fields SC, Heron JF (1997) Topotecan versus paclitaxel for the treatment of recurrent epithelial ovarian cancer. J Clin Oncol 15: 2183-2193

Whitacre CM, Zborowska E, Gordon NH, Mackay W, Berger NA (1997) Topotecan increases topoisomerase IIalpha levels and sensitivity to treatment with etoposide in schedule-dependent process. Cancer Res 57: $1425-1428$

Woessner RD, Mattern MR, Mirabelli CK, Johnson RK, Drake FH (1991) Proliferation- and cell cycle-dependent differences in expression of the 170 kilodalton and 180 kilodalton forms of topoisomerase II in NIH- 3T3 cells. Cell Growth Differ 2: 209-214 